\title{
Low charge state heavy ion production with sub-nanosecond laser
}

\author{
T. Kanesue ${ }^{1}$, M. Kumaki ${ }^{2,3}$, S. Ikeda ${ }^{3,4}$, M. Okamura ${ }^{1}$ \\ ${ }^{1}$ Collider Accelerator Department, Brookhaven National Laboratory, \\ Upton, NY 11973 USA \\ ${ }^{2}$ Research Institute for Science and Engineering, Waseda University, \\ Tokyo 169-8555 Japan \\ ${ }^{3}$ Nishina Center for Accelerator-Based Science, RIKEN, Saitama 351-0198 Japan \\ ${ }^{4}$ Interdisciplinary Graduate School of Science and Engineering, Tokyo Institute of \\ Technology, Kanagawa 226-8503 Japan
}

Presented at the $16^{\text {th }}$ International Conference on Ion Sources

New York Marriott Marquis Hotel, New York, NY

August 23 - 28, 2015

October 2015

\section{Collider-Accelerator Department Brookhaven National Laboratory}

\section{U.S. Department of Energy Office of Science, Office of Nuclear Physics}

Notice: This manuscript has been authored by employees of Brookhaven Science Associates, LLC under Contract No. DE-SC0012704 with the U.S. Department of Energy. The publisher by accepting the manuscript for publication acknowledges that the United States Government retains a non-exclusive, paid-up, irrevocable, world-wide license to publish or reproduce the published form of this manuscript, or allow others to do so, for United States Government purposes. 


\section{DISCLAIMER}

This report was prepared as an account of work sponsored by an agency of the United States Government. Neither the United States Government nor any agency thereof, nor any of their employees, nor any of their contractors, subcontractors, or their employees, makes any warranty, express or implied, or assumes any legal liability or responsibility for the accuracy, completeness, or any third party's use or the results of such use of any information, apparatus, product, or process disclosed, or represents that its use would not infringe privately owned rights. Reference herein to any specific commercial product, process, or service by trade name, trademark, manufacturer, or otherwise, does not necessarily constitute or imply its endorsement, recommendation, or favoring by the United States Government or any agency thereof or its contractors or subcontractors. The views and opinions of authors expressed herein do not necessarily state or reflect those of the United States Government or any agency thereof. 


\title{
Low charge state heavy ion production with sub-nanosecond laser ${ }^{\text {a) }}$
}

\author{
T. Kanesue ${ }^{1, b)}$, M. Kumaki, ${ }^{2,3}$ S. Ikeda, ${ }^{4,3}$ and M. Okamura ${ }^{1}$ \\ ${ }^{1}$ Collider-Accelerator Department, Brookhaven National Laboratory, Upton, New York 11973, USA \\ ${ }^{2}$ Research Institute for Science and Engineering, Waseda University, Tokyo 169-8555, Japan \\ ${ }^{3}$ Nishina Center for Accelerator-Based Science, RIKEN, Saitama 351-0198, Japan \\ ${ }^{4}$ Interdisciplinary Graduate School of Science and Engineering, Tokyo Institute of Technology, Kanagawa 226-8503, \\ Japan
}

(Presented XXXXX; received XXXXX; accepted XXXXX; published online XXXXX)

(Dates appearing here are provided by the Editorial Office)

\begin{abstract}
We have investigated laser ablation plasma of various species using a nanosecond and a sub-nanosecond laser for both high and low charge state ion production. We found that with sub-nanosecond laser, the generated plasma has long tail which is low charge state ions determined by an electrostatic ion analyzer even when the laser irradiation condition for highly charged ion production. This can be caused by insufficient laser absorption in plasma plume. This property might be suitable for low charge state ion production. We used a nanosecond laser and a sub-nanosecond laser for low charge state ion production to investigate the difference of generated plasma using Zirconium target.
\end{abstract}

\section{INTRODUCTION}

Recently, a laser ion source (LIS) for low charge state ion production has been intensively studied though the development of the LIS for heavy ion production was historically driven by the demand of highly-charged intense heavy ion beam for particle accelerators. To generate laser produced plasma containing low charge state ions, the laser power density on a solid state target is required to be less than about $10^{9} \mathrm{~W} / \mathrm{cm}^{2} .{ }^{1}$ The ion current can be enhanced by a solenoid field applied in a plasma expanding region. ${ }^{2}$ The LIS for low charge state heavy ion beam is used as an external ion source for an Electron Beam Ion Source (EBIS) or an Electron Cyclotron Resonance Ion Source (ECRIS) for further ionization. A LIS is suitable for this purpose because the LIS produces ions easily from almost all solid state materials, and ion species can be switched rapidly by changing the target position. At Brookhaven National Laboratory, the LION source has been used to provide multiple species of ion beam for the Relativistic Heavy Ion Collider-EBIS for NASA Space Radiation Laboratory and RHIC for user operation. ${ }^{3}$ Historically, lasers with the pulse width of nanosecond order, such as $\mathrm{CO} 2$ lasers or Nd-YAG lasers, have been used for the LIS development. ${ }^{4,5}$ This is because those lasers had suitable performances for particle accelerator applications, such as repetition rate, laser energy, and stability. However, recently lasers with shorter laser pulse with adequate performance has been

\footnotetext{
a) Contributed paper published as part of the Proceedings of the 16th International Conference on Ion Source, New York City, NY, August, 2015.

b) tkanesue@bnl.gov
}

commercially available and started to be used for the LIS development. The experimental result with sub- nanosecond laser for the high-charge state ion production showed that there was a low velocity tail containing low charge state ions. ${ }^{6}$ This result indicated that the use of subnanosecond laser could have an advantage for low charge state ion production. To verify the difference of the laser pulse width for low charge state ion production, the plasma properties produced by both nanosecond and subnanosecond were compared experimentally.

\section{EXPERIMENTAL SETUP}

The experimental setup was similar to the one shown in ${ }^{7}$. Two Nd:YAG lasers were used. The THALES laser SAGA230 (6 ns, maximum energy $2.3 \mathrm{~J}$ ) was used as a nanosecond (ns) laser, and the Ekspla laser SL330 (170 ps $\sim 570 \mathrm{ps}$, maximum energy $0.5 \mathrm{~J}$ ) was used as a subnanosecond (sub-ns) laser. The wavelength of both lasers is $1064 \mathrm{~nm}$. The Ekspla laser uses Backwardstimulated Brillouin scattering (SBS) to compress the laser pulse. The pulse width of 570 ps was used throughout the experiments shown below. A $0.25 \mathrm{~mm}$ thick Zirconium (Zr) foil with the dimension of $25 \mathrm{~mm}$ by $25 \mathrm{~mm}$ was used as a laser ablation target. The laser was focused by a focusing lens in a vacuum chamber onto the target with an incident angle of 20 degrees. The spot size on the target was $4.8 \mathrm{~mm}$ and $4.6 \mathrm{~mm}$ in diameter with the ns laser and the sub-ns laser, respectively. The ablation plasma generated by the laser irradiation adiabatically expands towards normal direction to the target surface. Because of the expansion, the ion current density decreases and the ion pulse width increases by following relations. ${ }^{4}$

$j \propto L^{3}$ 
$\tau \propto L$

(2)

where $j$ is current density, $L$ is a distance from the target, and $\tau$ is an ion pulse width. Total current of ions was measured by a Faraday Cup (FC) placed at $2.4 \mathrm{~m}$ from the target. The FC had a $10 \mathrm{~mm}$ in diameter opening and equipped with a mesh biased at $-3.5 \mathrm{kV}$ to extract ions from plasma and suppress secondary electrons from the cup. The charge state distribution was measured by an electrostatic ion analyzer (EIA) and a secondary electron multiplier (SEM) located at $3.8 \mathrm{~m}$ from the target. The vacuum pressure was kept at about $10^{-4} \mathrm{~Pa}$. The FC signal was used to convert the signal of each charge state analyzed by the EIA and SEM to beam current, assuming that the electron multiplication factor of the SEM is proportional to the ion charge

\section{RESULTS AND DISCUSSION}

The charge state distribution irradiated by the ns laser (1.0 $\mathrm{J})$ and the sub-ns laser $(0.10 \mathrm{~J})$ were measured to compare the difference of the laser pulse width under the condition with the similar laser power density. The laser power density on the target with the ns and sub-ns laser was $9.3 \times 10^{8} \mathrm{~W} / \mathrm{cm}^{2}$ and $1.0 \times 10^{9} \mathrm{~W} / \mathrm{cm}^{2}$, respectively. The same spot on the target was used in an experiment. The FC signal was checked before and after each experiment to ensure there was no significant change of the plasma properties.

We observed $\mathrm{Zr}, \mathrm{H}, \mathrm{C}$, and $\mathrm{O}$ ions. The results of the charge state measurement and the FC signal are shown in Fig. 1, and the ion yield of each ion species is shown in Fig. 2. In the figures, the measured charge state distribution and the FC signal were converted to those at $1 \mathrm{~m}$ from the target with $1 \mathrm{~cm}^{2}$ area using Eqs. 1 and 2. The first small peak of the FC signal consisted of light ions mainly $\mathrm{H}^{+}$, and $\mathrm{C}$ and $\mathrm{O}$ ions were found at the rising edge of the FC signal. The lower charge state distribution of $\mathrm{Zr}$ ions $\left(95.9 \%\left(\mathrm{Zr}^{1+}\right), 4.1 \%\left(\mathrm{Zr}^{2+}\right)\right.$, and $\left.0.01 \%\left(\mathrm{Zr}^{3+}\right)\right)$ was observed with the sub-ns laser irradiation, than that with the ns laser $\left(84.7 \%\left(\mathrm{Zr}^{1+}\right), 14.8 \%\left(\mathrm{Zr}^{2+}\right)\right.$, and $0.5 \%$ $\left.\left(\mathrm{Zr}^{3+}\right)\right)$. The beam pulse width with the sub-ns laser $(71 \mu \mathrm{s}$ for $\mathrm{Zr}^{1+}$ at $10 \%$ of the peak current) was longer than that of the ns laser ( $53 \mu$ s for $\mathrm{Zr}^{1+}$ at $10 \%$ of the peak current). In addition to $\mathrm{Zr}$ ions, Oxygen, Carbon, and Hydrogen ions were detected as impurities. To achieve the similar charge state distribution as the ns laser, the laser power density of the sub-ns laser was increased to $3.0 \times 10^{9} \mathrm{~W} / \mathrm{cm}^{2}$ by increasing the laser energy from 0.10 to $0.28 \mathrm{~J}$. The result of the increased laser power density with the sub-ns laser is shown in Fig. 3. The amount of $\mathrm{Zr}$ ions was $83.1 \%$ $\left(\mathrm{Zr}^{1+}\right), 16.2 \%\left(\mathrm{Zr}^{2+}\right)$, and $0.7 \%\left(\mathrm{Zr}^{3+}\right)$. The pulse width of the plasma was $59 \mu$ s for $\mathrm{Zr}^{1+}$ at $10 \%$ of the peak current. The charge state distribution and the pulse width were almost same as the ns laser experiment.
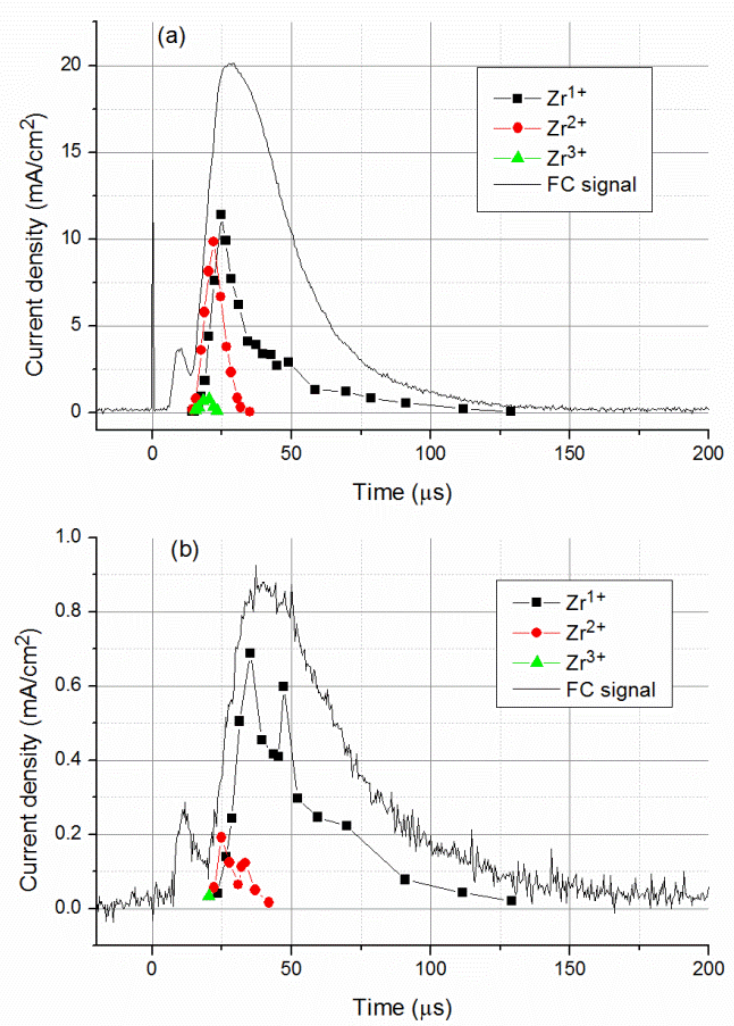

FIG. 1. Charge state distribution of $\mathrm{Zr}$ plasma produced by (a) ns laser $\left(9.3 \times 10^{8} \mathrm{~W} / \mathrm{cm}^{2}\right)$ and (b) sub-ns laser $\left(1.0 \times 10^{9} \mathrm{~W} / \mathrm{cm}^{2}\right)$.
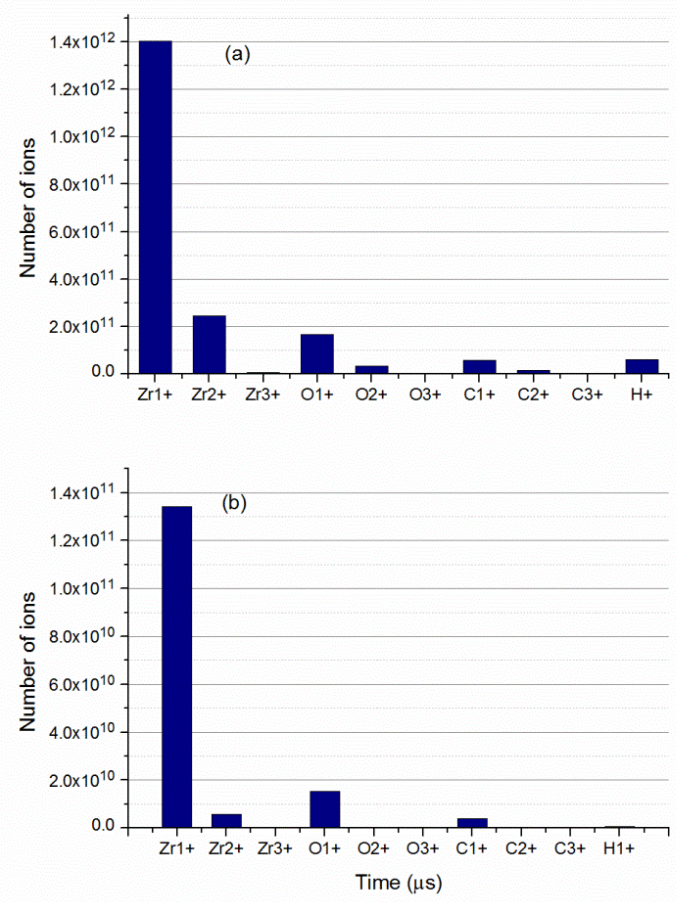

FIG. 2. Ion yield of each ion species produced by (a) ns laser $\left(9.3 \times 10^{8} \mathrm{~W} / \mathrm{cm}^{2}\right)$ and (b) sub-ns laser $\left(1 \times 10^{9} \mathrm{~W} / \mathrm{cm}^{2}\right)$. 
With the similar laser power density of about $1 \times 10^{9}$ $\mathrm{W} / \mathrm{cm}^{2}$, the sub-ns laser produced the lower charge state distribution and longer plasma than that of the ns laser. These results indicate that the plasma temperature was lower with the sub-ns laser than that with the ns laser. This can be because the laser pulse width is too short to develop the ion charge states in the plasma. With the increased laser power density of the sub-ns laser, the similar charge state distribution and the ion pulse width were observed. The plasma production process could be the same between the sub-ns and ns lasers with the adjusted laser power density. However, the sub-ns laser produced more ions of the impurities. These impurities were originated from the surface contamination. The first peak of the FC signal consisted of $\mathrm{H}^{+}$. The ratio of the first and second peak of the FC signal should be a measure of the amount of impurities. The ratio of the first and second peak current was 2.7 and 5.4 for the increased sub-ns laser and ns laser experiment, respectively. This suggested that the laser energy was more absorbed by the surface contamination than the $\mathrm{Zr}$ target. The ns laser was more efficient to generate $\mathrm{Zr}$ ions. The laser irradiation conditions are summarized in Table I.
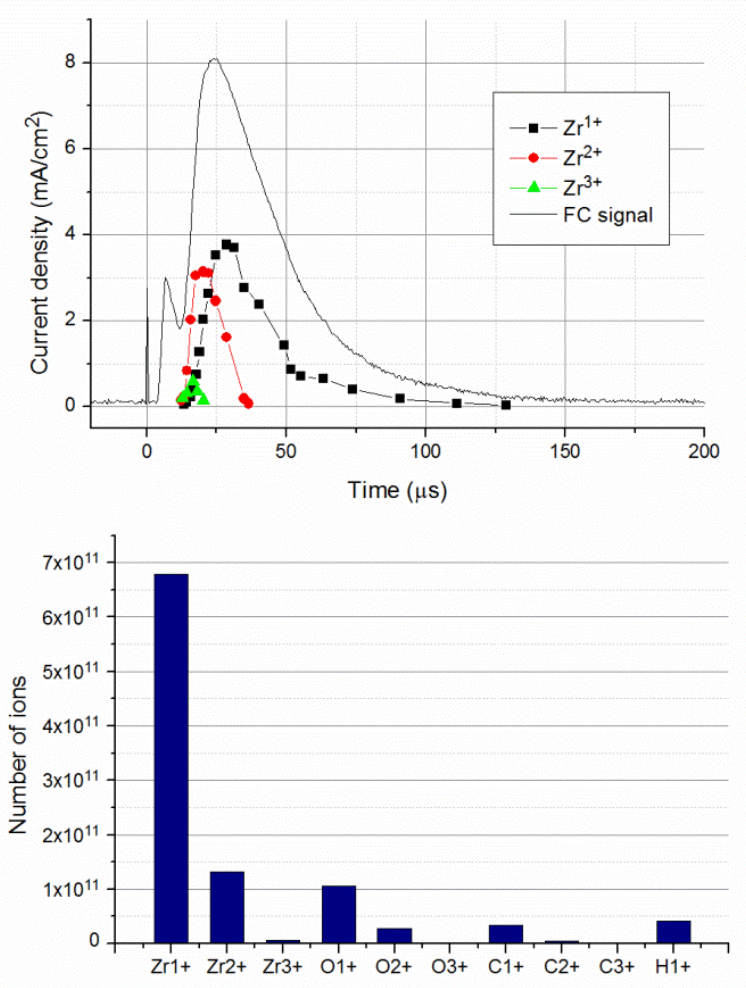

FIG. 3. Charge state distribution and ion yield produced by sub-ns laser with increased laser power density $\left(3.0 \times 10^{9} \mathrm{~W} / \mathrm{cm}^{2}\right)$.
TABLE I. Laser irradiation condition used in the experiments.

\begin{tabular}{|l|l|l|l|l|}
\hline Name & $\begin{array}{l}\text { Power } \\
\text { density } \\
(\mathrm{W} / \mathrm{cm} 2)\end{array}$ & $\begin{array}{l}\text { Laser } \\
\text { Energy } \\
(\mathrm{J})\end{array}$ & $\begin{array}{l}\text { Pulse } \\
\text { width } \\
(\mathrm{ns})\end{array}$ & $\begin{array}{l}\text { Spot size in } \\
\text { diameter } \\
(\mathrm{mm})\end{array}$ \\
\hline ns laser & $9.3 \mathrm{E} 8$ & 1.01 & 6.0 & 4.8 \\
\hline sub-ns laser & $1.0 \mathrm{E} 9$ & 0.10 & 0.57 & 4.6 \\
\hline $\begin{array}{l}\text { sub-ns laser } \\
\text { (increased } \\
\text { power density) }\end{array}$ & $3.0 \mathrm{E} 9$ & 0.28 & 0.57 & 4.6 \\
\hline
\end{tabular}

\section{CONCLUSION}

The laser ablation plasma of $\mathrm{Zr}$ generated by a sub-ns laser and ns laser was experimentally compared to see the difference of the laser pulse width for low charge state ion production. The results showed that with the same laser power density at about $1 \times 10^{9} \mathrm{~W} / \mathrm{cm}^{2}$ the sub-ns laser produced the lower charge state distribution and longer plasma than that of the ns laser. By increasing the laser power density of the sub-ns laser, the similar charge state distribution was obtained though more impurities were observed. For low charge state ion production, a ns laser can generate target ions more efficiently than a sub-ns laser.

\section{ACKKNOWLEDGEMENT}

This work was supported by the U.S. Department of Energy and the National Aeronautics and Space Administration.

${ }^{1}$ K. Kondo, T. Kanesue, J. Tamura, and M. Okamura, Rev. Sci. Instrum. 81, 02A511 (2010).

${ }^{2}$ K. Takahashi, M. Okamura, M. Sekine, E, Cushing, and P. Jandovitz, AIP Conference Proceedings 1525, 241 (2013).

${ }^{3}$ T. Kanesue, M. Okamura, J. Alessi, E. Beebe, A. Pikin, D. Raparia, CJ. Liaw, R. Lambiase, V. LoDestro, M. Costanzo, R. Lehn, L. DeSanto, R. Olsen, A. Steszyn, Proceedings of IPAC2014, Dresden, Germany 15-20 June, 2014, p.1890.

${ }^{4}$ B. Sharkov, and R. Scrivens, IEEE Transactions on plasma science, Vol. 33, No. 6, December 2005, p.1778.

${ }^{5}$ M. Okamura, T. Takeuchi, R. A. Jameson, S. Kondrashev, H. Kashiwagi, K. Sakakibara, T. Kanesue, J. Tamura, and T. Hattori, Rev. Sci. Instrum. 79, $02 B 314$ (2008).

${ }^{6}$ J. Badziak, P. Parys, A. B. Vankov, J. Wolowski, and E. Woryna, Appl. Phys. Lett. 79, 21 (2001).

${ }^{7}$ M. Kumaki, S. Ikeda, Y. Fuwa, D. Cinquegrani, M. Sekine, N. Munemoto, T. Kanesue, M. Okamura, and M. Washio, Rev. Sci. Instrum. 85, 02B925 (2014). 